AGH DRILLING, OIL, GAS • Vol. 32 • No. $1 \cdot 2015$

http://dx.doi.org/10.7494/drill.2015.32.1.201

\author{
Rafał Wiśniowski*, Dariusz Knez*, Lukasz Hytroś*
}

\title{
DRILLABILITY AND MECHANICAL SPECIFIC ENERGY ANALYSIS ON THE EXAMPLE OF DRILLING IN THE POMERANIAN BASIN**
}

\section{INTRODUCTION}

The development of drilling technology has been always oriented to cheaper and more efficient drilling methods. For the sake of minimizing the cost of drilling, attempts should be made to the shorten all operations and increase the rate of penetration (ROP). This could be achieved not only by developing the construction technology but also by materials used for the production of tools, and the drilling process itself. The first analytical tools based on the fundamental parameters of drilling, i.e. weight on bit (WOB), RPM, size of the bit and strength of the rock. Theoretically, the rate of penetration depends on these simple parameters, e.g. by increasing the rotations we should obtain better output as the tools are cutting a larger volume of rock in a unit of time. Consequently, higher WOB allows the teeth to penetrate deeper and cut a larger volume of rock. However, practical observations and experience verified this opinion. It was observed that not only simple mechanical parameters are of importance. It is also hydraulics, i.e. pressure and stream of mud which matter for the operating tool. Additionally the models started to be modified by such parameters as a description of rock formation, detailed design of the bit and its wear. Further development led to the more advanced mathematical models for the analyses and simulations based on complex sets of entry data [9]. The use of such models resulted in considerable drops of the cost of drilling and increase of average rates of penetration. Future work should be focused on new drilling trends [10].

* AGH University of Science and Technology, Faculty of Drilling, Oil and Gas, Krakow, Poland

** Research in project Optidrilltec supported by NCBiR in BlueGas program 


\section{THEORETICAL BACKGROUND}

The analyzed interval was drilled with a PDC tool in soft claystone intercalated with medium-hard clayey shales. The process of drilling with a PDC tool is frequently described with models for cutting bits. Such models describe two phenomena: cutting of the rock and wearing of the tool. The PDC bits are highly durable, thanks to which can be used for drilling long sections. Authors [7] indicate that the influence of the bit wear on the drop of rate of penetration in medium-hard rock is insignificant. This happens because the wearing of the tool in long drilling cycles, especially in soft and medium-soft sedimentary rocks is insignificant from the point of view of the obtained footage. When drilling short intervals, no wear which would have an effect on the obtained results is observed. Hence, the best results are obtained when using a PDC tool in medium-hard sedimentary rocks and without accounting for the bit wear, as in the analyzed case.

The process of drilling with cutting bits can be described with the momentary penetration rate in equations $(1-3)[3,6]$ :

$$
\begin{aligned}
& V=\left(V_{0}\right)^{-b t} \\
& V=V_{0} \cdot e^{-a t} \\
& V=\frac{V_{0}}{1+m t}
\end{aligned}
$$

where:

$$
\begin{aligned}
V & - \text { momentary rate of penetration }[\mathrm{m} / \mathrm{s}] \\
V_{0} & - \text { initial rate of penetration }[\mathrm{m} / \mathrm{s}] \\
b, a, m & - \text { coefficients of rate of penetration decrease, } \\
t & - \text { time of drilling }[\mathrm{s}]
\end{aligned}
$$

Authors [6] prove that an assumption of a minimal impact of the bit wear on ROP can be made for low and medium-hard sedimentary rocks. Accordingly, it can be further assumed that $V=V_{0}$, where $V_{0}$ is ROP for a bit which has not been worn away.

The initial value of the rate of penetration $V_{0}$, depends on the weight on bit, rotational velocity, rock properties and tool/rock interaction. Therefore a drillability coefficient is introduced [2] as it characterizes this system:

$$
\begin{gathered}
V_{0}=V=Z_{S P} \cdot P_{j}^{k} \cdot n^{r} \\
V_{0}=V=Z_{S P} \cdot P_{j} \cdot n^{\alpha} \\
V_{0}=V=A \cdot P_{j}^{\beta}
\end{gathered}
$$


where:

$$
\begin{aligned}
Z_{S P} & - \text { drillability coefficient, } \\
P_{j} & - \text { specific weight on bit }[\mathrm{N} / \mathrm{m}], \\
n & - \text { rotational velocity of bit }[1 / \mathrm{s}], \\
k, \beta & - \text { coefficients of WOB on initial value of ROP, } \\
r, \alpha & - \text { coefficients of impact of rotational velocity on initial ROP. }
\end{aligned}
$$

Drillability $Z_{S P}$ is a parameter describing the rock/bit system and always has positive values. This system is described with the use of two factors [4, 11], abrasiveness index, which has an effect on the bit wear, and the index of rock strength, which describes its resistance to drilling. The wearing of a bit is negligible, therefore $Z_{S P}$ is interpreted as a rock property in this model. The higher is the drillability of rock, the higher are the rates of penetration obtained with the same bit.

The MSE concept treats the drilling as a mechanical process characterized by mechanical energy balance [8]. MSE shows what work has to be done to drill a given volume of rock. The analysis of this parameter is helpful when optimizing the process of drilling as it allows to detect sections where the drilling was inefficient. MSE is given with the following formula [1]:

$$
\mathrm{MSE}=\frac{P}{A_{b}}+\frac{120 \pi \cdot n \cdot T}{A_{b} \cdot V}
$$

where:

$$
\begin{aligned}
A_{b} & - \text { surface of a bit of diameter } d\left[\mathrm{~m}^{2}\right], \\
P & - \text { weight on bit }[\mathrm{N}], \\
T & - \text { rotational torque }[\mathrm{N} \cdot \mathrm{m}], \\
\text { MSE } & - \text { Mechanical Specific Energy }[\mathrm{Pa}] .
\end{aligned}
$$

The coefficient of bit's sliding friction [5] was introduced to equation (7) in the following form:

$$
\mu=\frac{T}{d \cdot P}
$$

In practice the following values can be assumed for this coefficient, i.e. 0.25 for tricone bits, and 0.5 for PDC bits.

After introducing the sliding friction coefficient $\mu$ to equation (7), we have:

$$
\mathrm{MSE}=\frac{P}{A_{b}}+\frac{13.33 \cdot \mu \cdot n \cdot P}{d \cdot V}
$$


MSE is a very useful optimization tool; by reducing it we can observe a significant increase of the efficiency of drilling. Moreover, the analysis of MSE plots reveals in which places too much energy has been spent, thus increasing the cost, which is not necessary if we do not obtain a significant and profitable increase of ROP, or when it drops down. These simple formulae are easily applicable in field conditions in the process of drilling in realtime calculations.

\section{ANALYSIS OF DRILLING DATA}

Figures 1 and 3 present the real data from a wellbore in the Pomerania Basin. This is a set of two plots illustrating MSE, ROP and $Z_{S P}$ as a function of depth of the drilled wellbore. Figures 2 and 4 graphically represent the rotational velocity of the bit, WOB and gamma logs as a function of depth. The interval was drilled with the same tool, the lithologically is homogeneous and no failures or bit break-downs occurred. MSE and $Z_{S P}$ were calculated with formulae 4 and 9 on the basis of the measurement-while-drilling (MWD) data.

Interval $\mathrm{A}$ is deposited at 1650 to $1800 \mathrm{~m}$ of depth. The analysis of Figure 1 reveals that the bit operates in interval A at MSE only sporadically exceeding MSE of $250 \mathrm{MPa}$, and in a majority of cases is equal to about $100 \mathrm{MPa}$. ROP obtained in this interval ranges from 10 to 20 , sometimes $25 \mathrm{~m} / \mathrm{h}$. Drillability $Z_{S P}$ ranges from $0.25 \cdot 10^{-8} \mathrm{~m}^{2} / \mathrm{N}$ to $0.5 \cdot 10^{-8} \mathrm{~m}^{2} / \mathrm{N}$. Sometimes it may exceed both the lower and the upper limits.

The rotational velocity is about $210 \mathrm{rpm}$. WOB values oscillate between 40,000 to $80,000 \mathrm{~N}$ in the interval 1650 and $1725 \mathrm{~m}$, and from 20,000 to $45,000 \mathrm{~N}$ in interval 1725 and $1800 \mathrm{~m}$. Lower WOB would result in a slight decrease of ROP and a slight increase of MSE. The oscillations in WOB measurements result from the inertia of the system operating deep under the surface [5]. Gamma profiling shows that a tool operates in a lithologically homogeneous layer.

To a depth of $1950 \mathrm{~m}$ the system operates at low MSE at 200 to $250 \mathrm{MPa}$, only locally exceeding it. The rate of penetration oscillates between 15 and $30 \mathrm{~m} / \mathrm{h}$. The drillability is on an average level of $0.25 \cdot 10^{-8} \mathrm{~m}^{2} / \mathrm{N}$. However from a depth of $1950 \mathrm{~m}$ the MSE rapidly increases while ROP is maintained on a low level. This is accompanied by a drop of drillability. ROP decreases from a predefined level to values rarely exceeding $15 \mathrm{~m} / \mathrm{h}$ and in a majority of cases is below $15 \mathrm{~m} / \mathrm{h}$, to reach 5 to $10 \mathrm{~m} / \mathrm{h}$ in extreme cases. At the same time the drillability decreases to a level locally exceeding $0.3 \cdot 10^{-8} \mathrm{~m}^{2} / \mathrm{N}$, on average to $0.125 \cdot 10^{-8} \mathrm{~m}^{2} / \mathrm{h}$. Interestingly, MSE increases from about $250 \mathrm{MPa}$ to over $500 \mathrm{MPa}$, frequently reaching 750 , sometimes even $1000 \mathrm{MPa}$. This means that energy used for drilling rocks increased at least twice, sometimes even 4 times. 


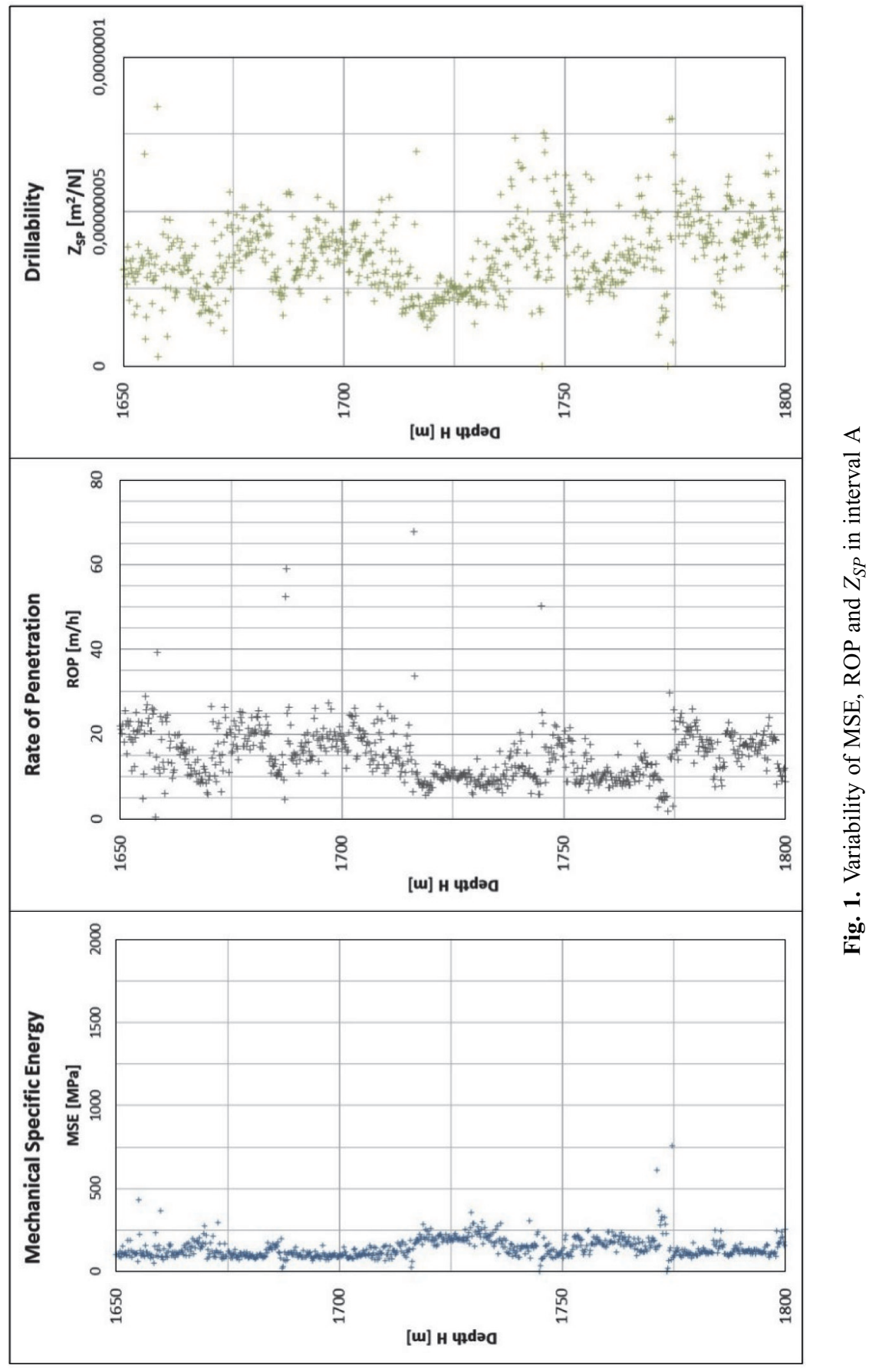




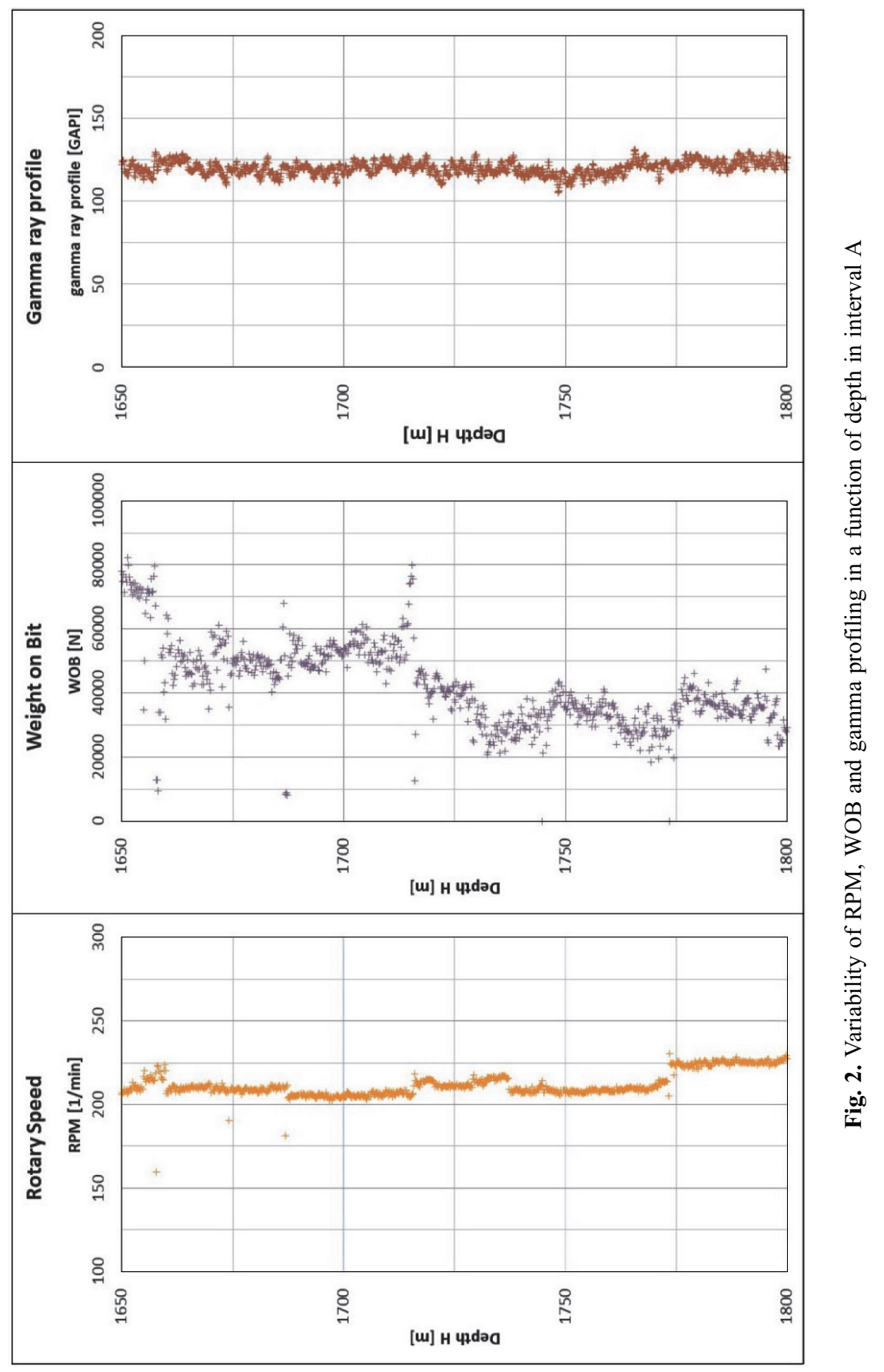




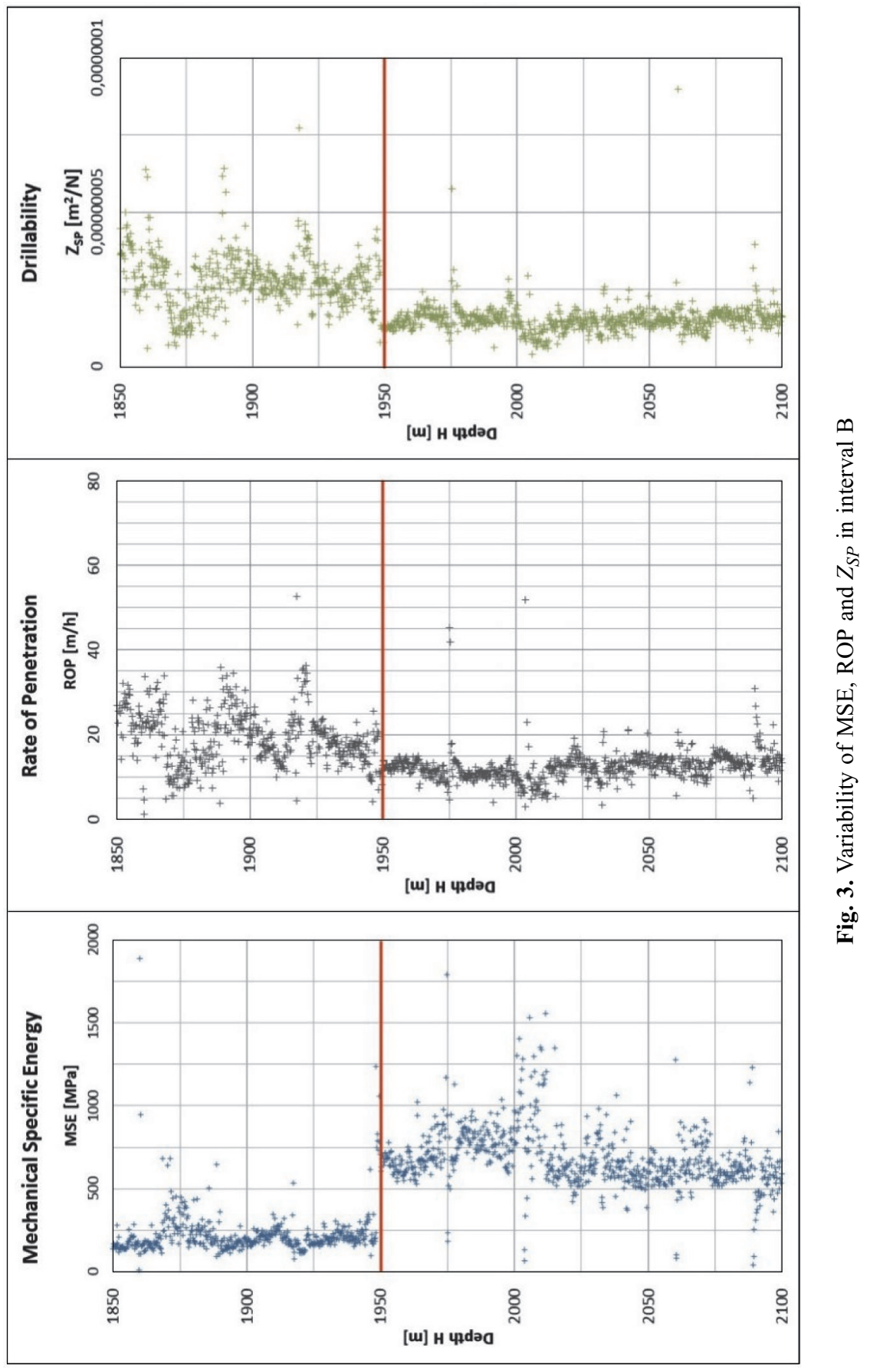




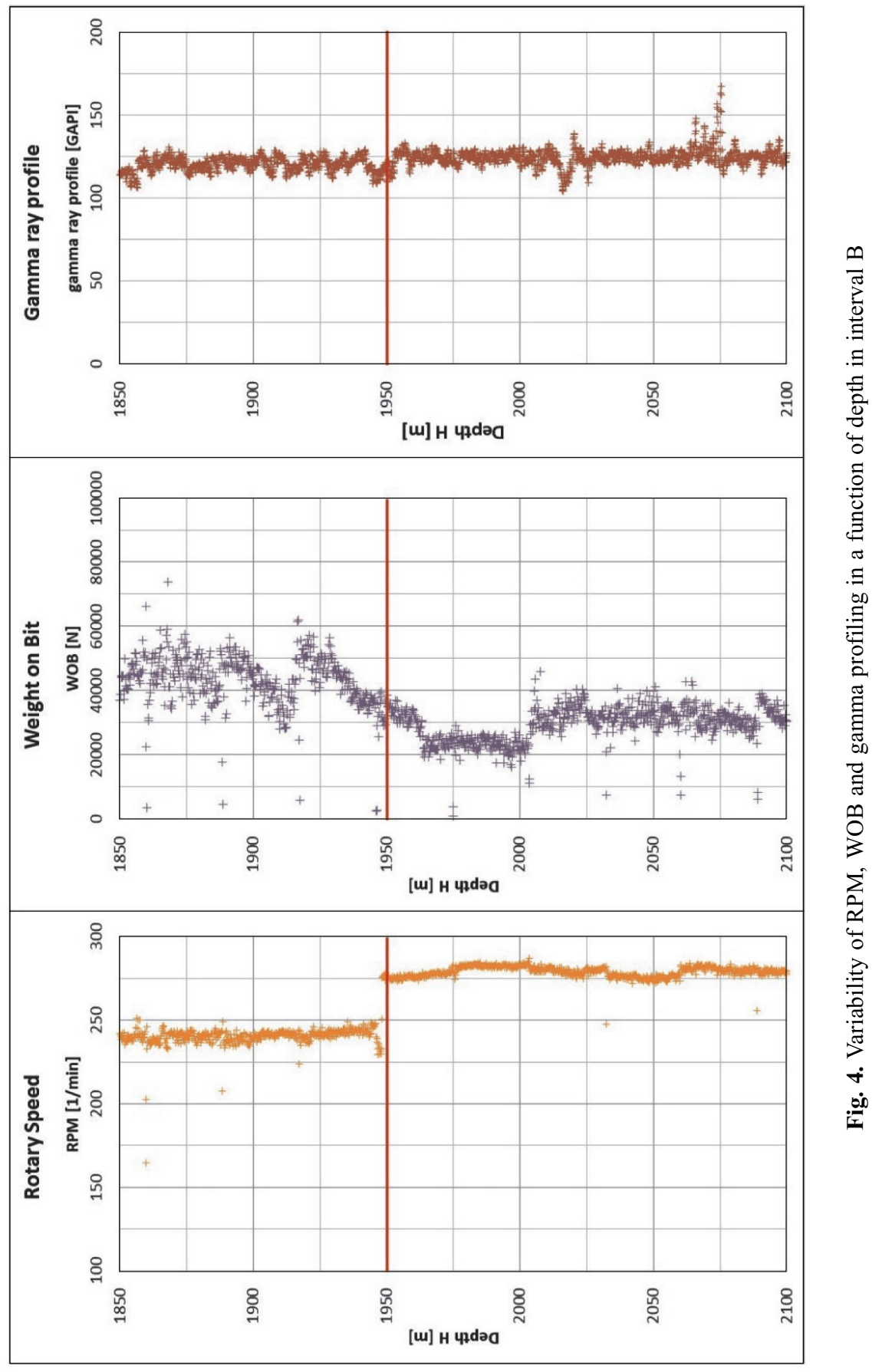


Additionally, the energy increase did not contribute to the higher rate of penetration, which is a very important information. For this reason the drop of $Z_{S P}$ does not have any connection with the change in lithology. Figure 4 shows the gamma profiling indications in the analyzed interval B. The indications do not change which means that the lithology is stable. This leads to the conclusion that the analysis of drillability changes as a variability of rock hardness or damaged tools may lead to erroneous conclusions. These conclusions may result in considerable energy losses when WOB and RPM have not been properly adjusted. This can be seen on the MSE plot of energy used in the process of drilling of a given volume of rock.

The analysis of drilling parameters revealed that the area of MSE increase and drop of ROP and $Z_{S P}$, correlates with the area where the bit rotations were increased. This is visualized in Figure 4. The change of drillability of rock was a result of changes of drilling parameters without optimization properly performed, not a change of rock properties or damaged tool, as could be expected without examining the MSE plot.

\section{CONCLUSIONS}

1. In the case of sedimentary rocks the bit wearing can be ignored, thanks to which $Z_{S P}$ can be erroneously interpreted as the only parameter depending on the rock hardness.

2. The MSE concept describes the amount of energy used for drilling a given volume of rock, thanks to which the interval of inefficient bit operation can be detected.

3. MSE is the energy used for drilling, therefore economic aspects in view, minimum MSE values and maximum ROP values are recommended.

4. In interval A the system operated at low MSE. This resulted from the correctly assumed drilling parameters for the drilled rock in given conditions.

5. In interval B the energy of the operating bit increased at least twice, however ROP did not increase but dropped down.

6. Despite operator's expectations, the higher number of RPM's with which the tool operated in interval B did not increase ROP, except that more energy was consumed.

7. The comparison of MSE with $Z_{S P}$ clearly proves that drillability not always can be interpreted as a indicator of mechanical property of the rock or bit wear.

8. In drilling practice more parameters should be monitored in real-time to quickly correct the drilling technology parameters.

\section{REFERENCES}

[1] Armenta M.: Identifying Inefficient Drilling Conditions Using Drilling-Specific Energy. SPE 116667, Denver, USA, 2008.

[2] Gonet A.: Optymalizacja mechanicznych parametrów technologii wiercenia otworów świdrami skrawajacymi. Przegląd Górniczy, nr 5, 1995. 
[3] Gonet A., Zięba A., Pawlikowska J., Wójcik M.: Technika i technologia rdzeniowania otworów. Skrypty Uczelniane 1451, Wydawnictwa AGH, Kraków 1996.

[4] Mensa-Wilmot G., Fear M.J.: The Effects of Formation Hardness, Abrasiveness, Heterogenity and Hole Size on PDC Bit Performance. SPE/IADC 67698, Amsterdam, The Netherlands, 2001.

[5] Pessier R.C., Fear M.J.: Quantifying Common Drilling Problems with Mechanical Specific Energy and Bit-Specific Coefficient of Sliding Friction. SPE 24584, Washington DC, USA, 1992.

[6] Rado R., Lubaś J.: Optymalizacja procesu wiercenia narzędziami PDC o średnicy 81/2. Wiertnictwo, Nafta, Gaz, t. 26, z. 1-2, Kraków 2009.

[7] Rado R., Lubaś J.: Próba wyznaczenia modelu wiercenia narzędziami PDC na przykładzie wiercenia $w$ wybranych strukturach geologicznych. Wiertnictwo, Nafta, Gaz, t. 24, z. 1, Kraków, 2007.

[8] Rafatian N., Miska S., Ledgerwood III L.W., Ahmed Ramadan, Yu Mengjiao, Takach N.: Experimental Study of MSE of a Single PDC Cutter Under Simulated Pressurized Conditions. SPE/IADC 119302, Amsterdam, The Netherlands, 2009.

[9] Rastegar M., Hareland G., Nygaard R., Bashari A.: Optimization of Multiple Bit Runs Based on ROP Models and Cost Equation: A New Methodology Applied for One of the Persian Gulf Carbonate Fields. SPE 114665, Jakarta, Indonesia, 2008.

[10] Śliwa T., Mazur M., Gonet A., Sapińska-Śliwa A.: Hammers-rotary drilling for geoenergetics. Wiertnictwo, Nafta, Gaz, t. 28, z. 4, 2011, 759-770.

[11] Ziaja M., Miska S.: Mathematical Model of the Diamond-Bit Drilling Process and Its Practical Application. SPE 10148, San Antonio, USA, 1981. 